\title{
Disassembly of waste printed circuit boards using air heating and centrifugal force
}

\author{
Desmontagem de placas de circuito impresso usando ar quente e força centrífuga
}

\author{
Ricardo Soares Rubin', Marco Aurélio Soares de Castro", Dennis Brandão"II
}

\section{Abstract}

Waste electrical and electronic equipment is a significant source of material that can contribute to reduce environmental impacts associated to extraction and discard stages; therefore, it is necessary to develop efficient recycling processes for components such as Printed Circuit Boards (PCBs). Current methods for PCB recycling may be optimized by previous disassembly of such components. In the work reported here, an especially designed and manufactured centrifuge was employed to disassemble PCBs from power supplies (PS-PCBs) and memory chips (MEPCBs) of personal computers (PCs), through combination of hot air flow and centrifugal force. The results showed that the device was capable of separating tin solder, electronic components (EC) and PCB substrate, as long as hazardous components and plastic parts are previously removed. A scanning electron microscope (SEM) with combined energy dispersive X-ray (EDX) analyzer showed that the recovered solder had under 3\%wt of contamination; therefore, it can be employed in the production of new soldering material, replacing the more commonly used solder dross. EC recovery rates were up to $94 \%$ wt for PS-PCBs and 32\%wt for ME-PCBs, and once components such as inductors were not visibly damaged in the process, possibilities of reusing recovered components may be further investigated.

Keywords: Waste Electric and Electronic Equipment; Recycling; Disassembly

\section{Resumo}

Os Resíduos de Equipamentos Eletrônicos são uma fonte significativa de material que pode contribuir para reduzir impactos ambientais das etapas de extração e descarte; portanto, é necessário desenvolver processos de reciclagem eficientes para componentes como as placas de circuito impresso (PCIs). Os métodos atuais de reciclagem de PCIs podem ser otimizados pela prévia desmontagem desses componentes. Neste trabalho, uma centrífuga foi especialmente projetada e fabricada para desmontar PCIs de fontes (PS-PCBs) e chips de memória (ME-PCBs) de computadores pessoais, por meio da combinação de fluxo de ar quente e centrifugação. OS resultados mostraram que o equipamento foi capaz de separar solda, componentes eletrônicos (ECs) e substratos das placas, contanto que componentes perigosos e partes plásticas sejam previamente removidos. Análises com microscópio eletrônico de varredura com módulo de energia dispersiva de raio-x integrado mostraram que a solda recuperada apresentou menos de $3 \%$ em massa, de contaminação, podendo assim substituir a borra de solda comumente usada na produção de novas soldas. As taxas de recuperação de componentes chegaram a $94 \%$ no caso das PS-PCB e 32\% para as ME-PCBs, e uma vez que componentes como os indutores não foram visivelmente danificados no processo, as possibilidades de reutilizá-los podem ser investigadas.

Palavras-chave: Resíduos de Equipamentos Eletrônicos; Reciclagem; Desmontagem 


\section{Introduction}

Although sales of PCs and tablets have been decreasing consistently since 2014 , and the laptop market has been recovering lightly since 2016, more than 357 million units of these devices were shipped only last year (Statista, 2018). Significant sales numbers are still a reflex of factors such as constant technology updating, which causes the linear 'extraction-production-usage-disposal' chain to be more resource intensive, while also increasing emission to air, weather and soil. Waste electrical and electronic equipment (WEEE) contains substances that are high-valued and/or highly toxic, and for this reason it is a great source of valuable materials and, at the same time, a vehicle for hazardous substances to impact environment and human health (Puckett and Smith, 2002; UNEP, 2009).

Legal requirements of developed and developing countries, such as Brazil, establish that WEEE must be reused or recycled as extensively as possible, through adequate and technically feasible alternatives. Brazilian Policy on Solid Waste is yet to be fully implemented, and the lack of consistent estimates on WEEE generation and collection infrastructures for Reverse Logistics Systems remain among the several barriers to overcome. Almost $90 \%$ of the Brazilian recycling companies only undertake sorting and dismantling, and more than $90 \%$ of them perform this operation manually; also, WEEE whose recycling process is more complex is still sent to foreign downstream companies (Dias et al., 2018).

One fundamental step of WEEE recycling processes is the disassembly of such equipment in its constituents, such as Printed Circuit Boards (PCBs). Despite accounting for only about $6 \%$ of the total weight of WEEE, PCBs might be considered a high value waste, namely a source for copper (Bleiwas and Kelly, 2001; Das et al., 2009), and even tin and lead, which are still found in solders (Almeida et al., 2013). However, PCBs also contain several toxic substances like lead, beryllium, cadmium, arsenic and even - in the case of older PCBs - brominated flame retardants; several researches have focused on strategies for recovering the precious metals and removing such harmful elements, often using high tech equipment and demanding large investments (Hanafi et al., 2012).

Many PCB recycling technologies and methods have been developed, usually by combining shredding or crushing with pyrometallurgical or hydrometallurgical processes, which require some kind of separation and refining operations. In fact, processes with higher metals recovery rates are usually comprised of three steps: pretreatment (composition analysis and selective disassembly), size reduction and materials separation by mechanical/physical processing and refining/purification by metallurgical / chemical processes (Kaya, 2016).

Separation involves a comminution process, in which PCB scrap is shredded and/or crushed in a hammer mill for homogenization and particle size reduction (Li et al., 2004; Veit et al., 2005; Hino et al., 2009; Long et al., 2010). Crushing can also be performed in a wet crushing equipment, such as hammer mill with water medium, which can help control the fugitive odors and dust emissions, while avoiding excessive temperature in parts of the mill during the process (Duan et al., 2009).

To maximize the concentration of the target material, metals must be separated from non-metals after comminution. Separation methods as incineration and acid bathing may release hazardous substances in environment. Physical separation techniques, despite being energy intensive, are able to produce streams of metals and non-metals while being comparatively more eco-friendly and safe to operate. These techniques include screening, shape separation, magnetic separation, electric conductivity-based separation and density-based separation. (Furuuchi and Gotoh, 1992; Koyanaka et al., 1997; Cui and Forssberg, 2003; Park and Fray, 2009; Long et al., 2010).

Pyrometallurgical or hydrometallurgical refining processes separate the target metals from the rest (Yu et al., 2009; Youssef et al., 2012). The former is the traditional $\mathrm{PCB}$ recycling method, however it requires large-scale facilities and consequently large upfront investments (Yu et al., 2009); such processes are energy intensive and may generate uncontrolled harmful products (Youssef et al., 2012), while achieving only partial separation of metals. Hydrometallurgical processing involves acidic or caustic leaches of waste materials, and the recovery of metals from the leachates (Yu et al., 2009). They usually require smaller scales and less investment, while providing good recovery, selectivity and high purity output (Youssef et al., 2012). However, they may pose a considerable environmental impact due to the toxicity of the reagents, and the large amount of by-products, which demand additional investment on waste and water treatment (Yu et al., 2009).

Previous PCB disassembly can improve subsequent separation and refining operations (Cui and Forssberg, 2003; Veit et al., 2006; Xu et al., 2009); it consists in removing hazardous parts and electronic components from PCBs after solder is removed by thermal or chemical process (Kaya, 2018). ECs dismantling helps to overcome difficulties of subsequent treatments and improves the treatment capacity (Wang et al., 2017), and is one of the most important steps in the recycling process for that reason (Ghosh et al., 2015). Primitive thermally melting solders and manual disassembly have been used to separate of ECs from waste PCBs substrate (Wang et al., 2017); such step is not performed in large scale PCB recycling plants (Hagelüken, 2006), as it constitutes the major cost element and time consuming operation in e-waste recovery technology (Kaya, 2018). It also causes severe environmental pollution, posing a threat to human health (Guo et al., 2016).

Several studies discuss the improvement of selective disassembly. The main aspects for automatic disassembly optimization are junction technologies, components, assembly and layout (Bradstotter, 2004); another aspect to be considered is the adhesion of components to PCB substrate, which is influenced by number of pins, number of bent pins, bending angles, materials that the pins are made of, relation between hole and pin diameter and friction between the surfaces of the holes and the pins (Feldmann and Scheller, 1995). 
Some devices for selective disassembly have already developed; one of them is an automated part removal apparatus that contain two heating units, one providing removal force in vertical direction and the other in horizontal direction; a third unit does an abrading process for removal of the remaining solder (Iji and Yokoyama, 1997). No information on energy consumption, cost and processing capacity is provided. More recently, disassembly was performed on a prototype with four diamond grinders that wear down the solder joints on the backside of PCBs releasing components. The outputs were ECs, substrate and abrasion powder; copper and solder are mixed with substrate in the abrasion powder, requiring additional steps to be recovered (Lee et al., 2012).

Successful disassembly requires the integration of two main procedures: heating and displacement of components (Feldmann and Scheller, 1995; Layiding et al., 2005). The benefits of employing air heating are low cost, cleanness and heating mildness, while laser and infrared would have to prove themselves as cost and time efficient before practical application - the former, for example, is not usable for simultaneous dismantling and requires high energy consumption (Feldmann and Scheller, 1995; Layiding et al., 2005).

As for displacement, Yang et al. (2009a) concluded that a small removal force is required for dismantling surface mounted devices (SMDs); through hole devices (THDs) require insignificant removal force, but it increases with the pin bend angle.

ECs attached to PCBs through soldering can be dismantled by solder melting (Li et al., 2004). Solder can also be removed from PCBs for metal recovery purposes, including the production of new soldering material (Almeida et al., 2013). An assessment of recycling of lead solder dross generated in PCB manufacturing revealed that the chemical composition of the metal phase (about $74 \%$ of the dross) was $59.36 \%$ Sn and $40.44 \% \mathrm{~Pb}$, which indicates it might be used again, even in PCB production (Lucheva et al., 2011). In addition, recovery of tin solder from WEEE is an alternative to natural extraction: the amount of tin in the ore is about $0.01 \%$ in weight, while tin concentration after mill processing and separation reaches $70-77 \%$. Refining reduces tin oxide to impure metal and then to a high purity metal (99.75\% to $99.85 \%)$ (Lyman and Gerlach, 1954). By recovering metal, recycling helps reducing resource consumption, leading to significant environmental savings (Bigum et al., 2012).

Several methods have been used for melting solder, such as hot air, heated medium and infrared ( $\mathrm{Li}$ et al., 2014). Meng et al. (2018a) combined centrifugal separation with air heating, to recover copper from PCBs previously comminuted by crushing and screening; the best recovery rates were obtained at a temperature of $1300^{\circ} \mathrm{C}$, gravity coefficient of 1000 (that is, 1000 times the Earth's gravity), after 5 minutes of operation. The apparatus developed by Park et al. (2015) seeked only PCB disassembly: the boards were heated up to $250{ }^{\circ} \mathrm{C}$ via an infra-red heater in order to melt the solder, and rotating steel brush rods swept off the ECs. The removal rate reached $94 \%$; also, solder was not recovered.
Recovering ECs from PCBs is an aspect of the disassembly process still not sufficiently addressed. Especially due to the rising WEEE generation, recovery of all EC constituents should be explored and not remain limited to major and precious elements (Lee et al., 2012), especially since many components in scrapped or rejected PCBs are still functional and usable (Duan et al., 2011).

Rocchetti et al. (2018), on their patent review on PCB recycling, stated that the scientific literature focuses on three main aspects of PCB recycling: separation methods, hydrometallurgical processes and non-metals recovery. They identified a peak of interest on these aspects in the 2010s, and a decrease after that period. At the same time, pre-treatment operations, such as EC removal and EC separation and tin recovery (with or without previous solder melting) remained insufficiently addressed, despite the technological evolution of PCB valorization also identified in the review (Rocchetti et al., 2018).

Regarding the potential impacts of WEEE recycling processes, even though dioxins may be generated at $300^{\circ} \mathrm{C}, \mathrm{PBDD} / \mathrm{Fs}$ and $\mathrm{PCDD} / \mathrm{Fs}$ may be generated during incineration of $\mathrm{PCBs}$ at temperatures over $250^{\circ} \mathrm{C}$, when subjected to air atmosphere (Duan et al., 2011). A semi-automatic disassembly machine, combining heated air to melt solder and pulse jet was employed to separate ECs from waste PCBs, however the use of compressed air could increase risk of device explosion (Chen et al., 2013). On a subsequent study, a rotating cylinder and a vibrating screen replaced the pulse jet system, and an off-gas purification device was added; environmental impacts were not assessed, but since the operating temperature was lower than the critical limit of $250^{\circ} \mathrm{C}$, the study concluded that little emissions were generated (Wang et al., 2016).

The goal of the research reported here was to develop and apply a method for PCB disassembly, by combining air heating and centrifugal force, in order to obtain three streams: solder, EC and substrate.

\section{Materials and methods}

The disassembly process under investigation was performed on a dry medium, whose advantage is the non-generation of wastewater, a major concern of processes involving aqueous solutions. It was comprised of two main steps: first, PCBs were exposed to a hot air flow until the solder fusion point was reached, and after that a centrifugal force was applied to separate solder and ECs from the substrate. Both steps were performed on an apparatus specifically designed and manufactured, showed in Figure 1. It consisted of a centrifuge powered by a three-phase motor; two common air blowers inserted at the lid provided heating. A collector in hexagonal shape and a stainless steel basket with $0.7 \mathrm{~mm}$ diameter holes were mounted inside the centrifuge to retain components, as seen on Figure 2; a hole at the bottom of the collector helped to collect the melted solder after it passed through the basket holes (Figure 3).

Four screws help fixing the collector to the base 
Figure 1 - Prototype for PCB disassembly

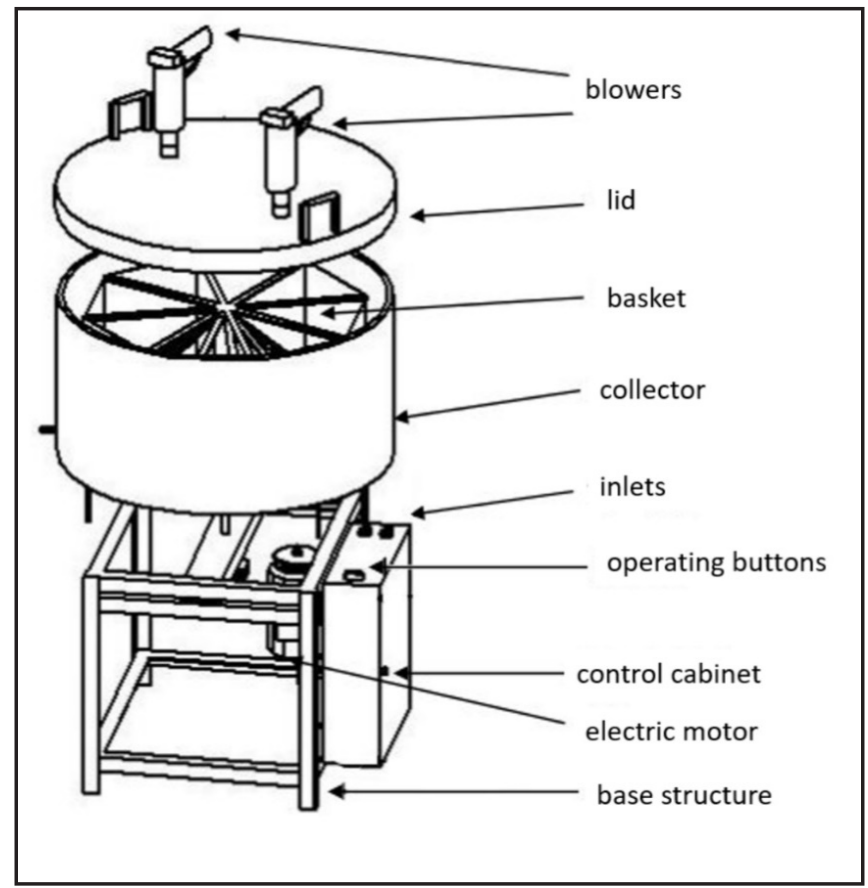

Figure 2 - Inside view of the centrifuge

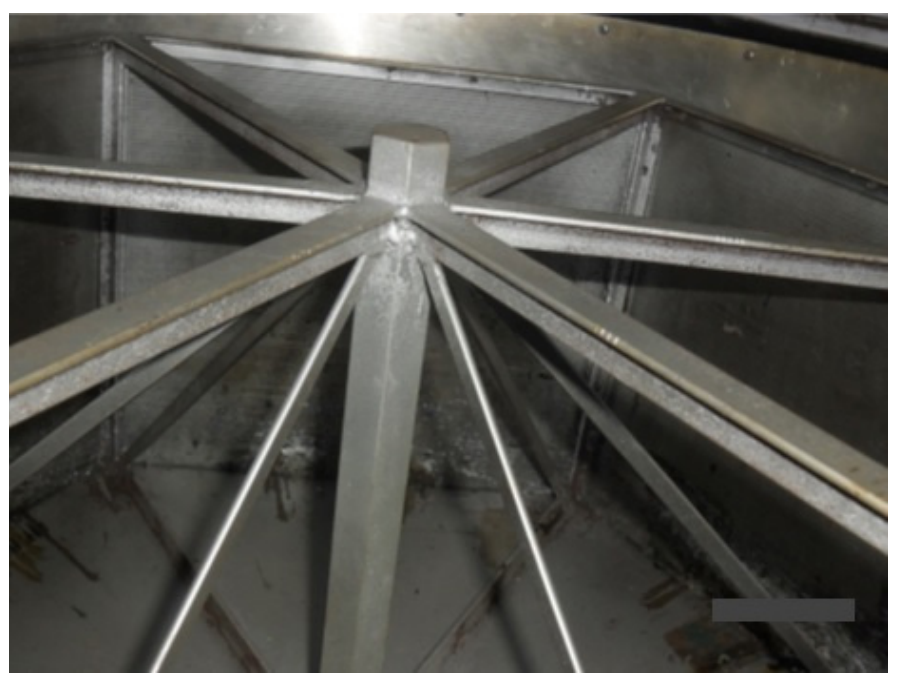

Figure 3 - Hole for solder collection

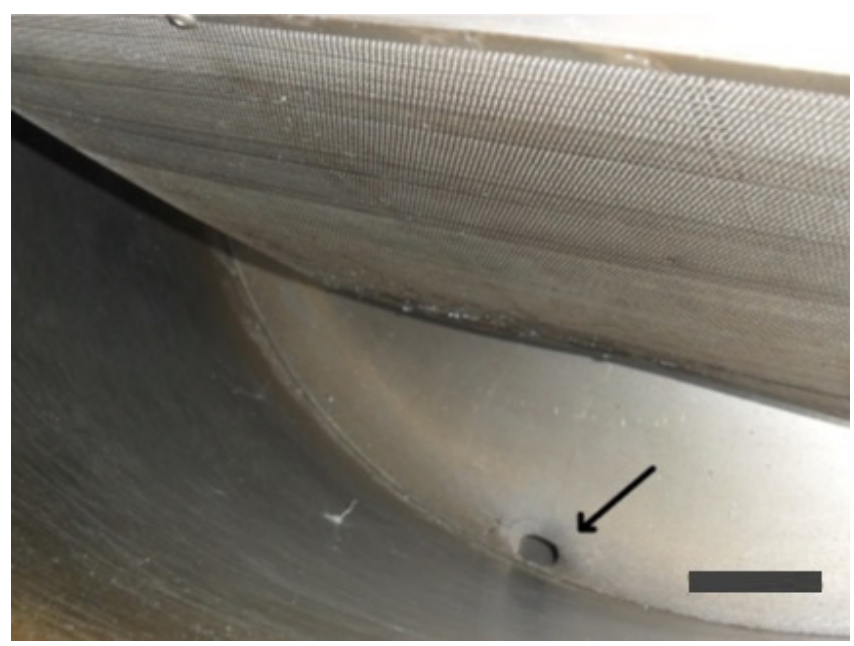


structure, as well as adjusting it with a small inclination to facilitate the solder to flow to the collection hole. The external wall of the centrifuge was made of a thermal insulator between two aluminum sheets, in which three thermocouples were placed. A Programmable Logic Controller (PLC) housed in a control cabinet controlled the operating time of the blowers - and therefore the temperature inside the collector - , as well as the rotating speed through a frequency inverter.

The PCBs used in the study were removed manually from power supply (PS) and RAM memories (ME) of obsolete PC's. PS-PCBs or very low grade boards were made of phenolic resin and paper containing one layer (copper sheet) with THT (Through Hole Technology) components, while ME-PCBs or very high grade boards were made of fiberglass with two layers (copper sheets) with THT and/or SM (Surface Mounted) IC chips. PCBs had heterogeneous structure and contained a variety of components such as condensers, IC chips, transistors, fuses, resistors, diodes and transformers; cables, capacitors, heat sinks and some plastic components were also manually removed.

The disassembly operations were performed on batches of six PS-PCBs or $20 \mathrm{ME-PCBs.} \mathrm{Prior} \mathrm{to} \mathrm{each}$ disassembly operation, $\mathrm{PCB}$ were placed inside the basket as shown in Figure 4; the centrifuge was closed

Figure 4 - PCB positioning inside the prototype

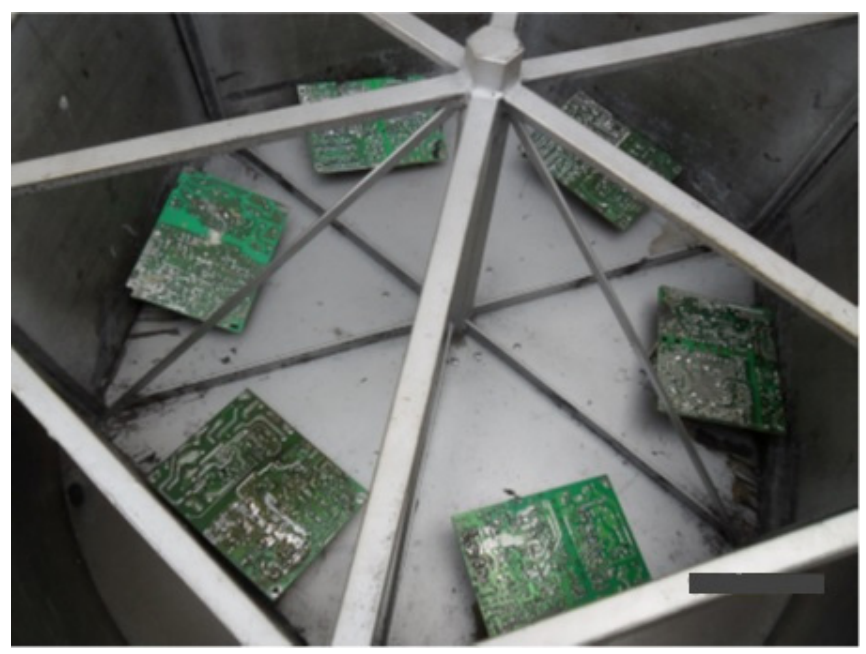

Figure 5 - Disassembly operation steps

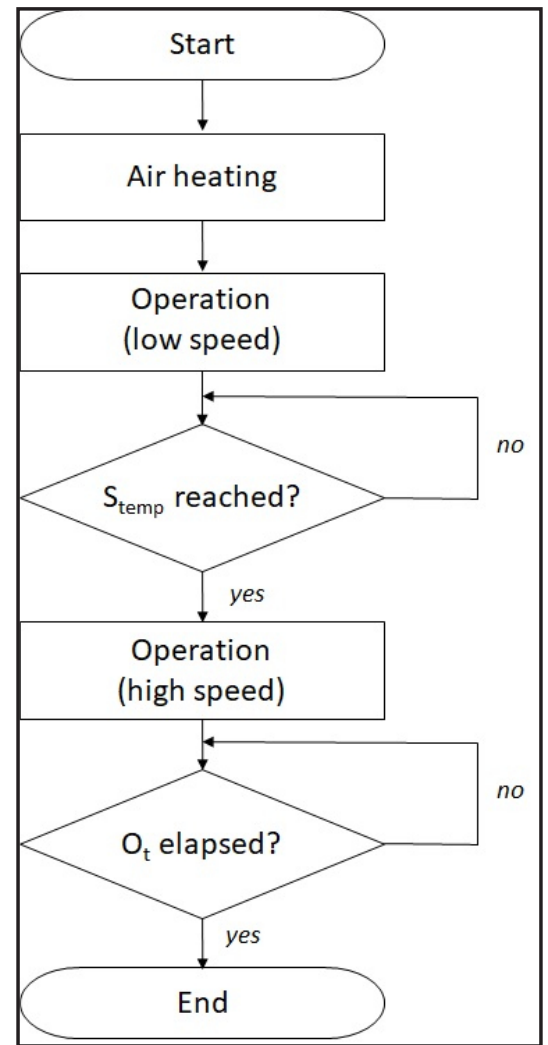


and the blowers were turned on.

In order to improve circulation of heated air inside the prototype, it was set to start operating at a lower rotation $(90 \mathrm{rpm})$. The centrifuge started rotating at this speed while the heated air circulated on the inside. When it reached a setpoint temperature $\left(S_{\text {temp }}\right)$, the disassembling process itself started: rotation speed was increased and maintained for a certain operation time $\left(\mathrm{O}_{\mathrm{t}}\right)$; according to Layiding et al. (2005), a value of 30 seconds was adopted as $\mathrm{O}_{\mathrm{t}}$. Air blowers were kept on during this stage, to maintain a high temperature even after higher rotation increased airflow on the inside. When $\mathrm{O}_{t}$ had elapsed, the PLC turned the prototype off.

Figure 5 summarizes the operation steps; $S_{\text {temp }}$, low and high rotation speeds and $\mathrm{O}_{t}$ can be adjusted via the PLC.

Results of initial tests helped define high rotating speeds ranging from $700 \mathrm{rpm}$ to $1100 \mathrm{rpm}$. On centrifugation processes, the gravity coefficient $G$ can be calculated in terms of the rotating speed $N$, the radius (distance from the axis to the center of the sample) $R$ and the normal gravitation acceleration $g$ via (1) (Meng et al, 2018b):

In the case of the apparatus, $R=0,34 \mathrm{~m}$, which yielded

$$
G=\frac{\sqrt{g^{2}+\left(N^{2} \pi^{2} R\right)^{2}}}{g}
$$

the values for $G$ presented on Table 1:

Table 1 - Gravity coefficients

\begin{tabular}{c|c}
\hline Rotating speed N (rpm) & Gravity coefficient G \\
\hline 700 & 186,24 \\
800 & 243,25 \\
900 & 307,86 \\
1000 & 380,07 \\
1100 & 459,89 \\
\hline
\end{tabular}

Regarding the operation temperature, ranges for both ME and PS boards started at $180^{\circ} \mathrm{C}$ (typical solder fusion point) and went up to the point when smoke was generated and the boards became deformed; for PS boards this point was reached at $220^{\circ} \mathrm{C}$, while for ME boards the upper limit was $240{ }^{\circ} \mathrm{C}$.

PCBs were weighted before the procedure, as well as the three outputs: solder, EC and substrate. Contents of the recovered solder were determined using a scanning electron microscope (SEM) with combined energy dispersive X-ray (EDX) analyzer.

The chosen PCBs contained only metallic and ceramic components. Preliminary tests also indicated the necessity of removing all plastic parts from PCBs before their disassembly; due to their low fusion temperature $\left(105^{\circ} \mathrm{C}\right.$ for polyethylene and $130^{\circ} \mathrm{C}$ for polyacetal), plastics melted before solder and tended to form a grout among EC, solder and the inside of the prototype.

The recovery rates of solder and EC's from PS-PCBs were analyzed as a function of temperature and rotating speed. Recovered solder and EC's were weighted and the percentages were calculated considering the total mass of the sample initially placed in the prototype (without cables, capacitors, heat sinks and some other plastic components which were manually removed).

\section{Results and discussion}

Figure 6 shows the results for solder recovery; mean values oscillate between $1.38 \%$ and $2.86 \%$ with a linear growing with the increase of temperature. Solder recovery increased with rotating speed until $900 \mathrm{rpm}$ and stayed constant for higher values. The values over $4 \%$ were attributed to the liberation of solder which had been adhered to the collector in previous operating cycles.

Recovery rates of EC are show in Figure 7 as a function of temperature. The amount of recovered EC grows steadily until $200^{\circ} \mathrm{C}$, despite a great variation on lower temperatures, and stabilizes from that point on, regardless of the rotation speed. Also, EC recovery rates presented a

Figure 6 - Solder recovery rates during PS-PCB disassembly

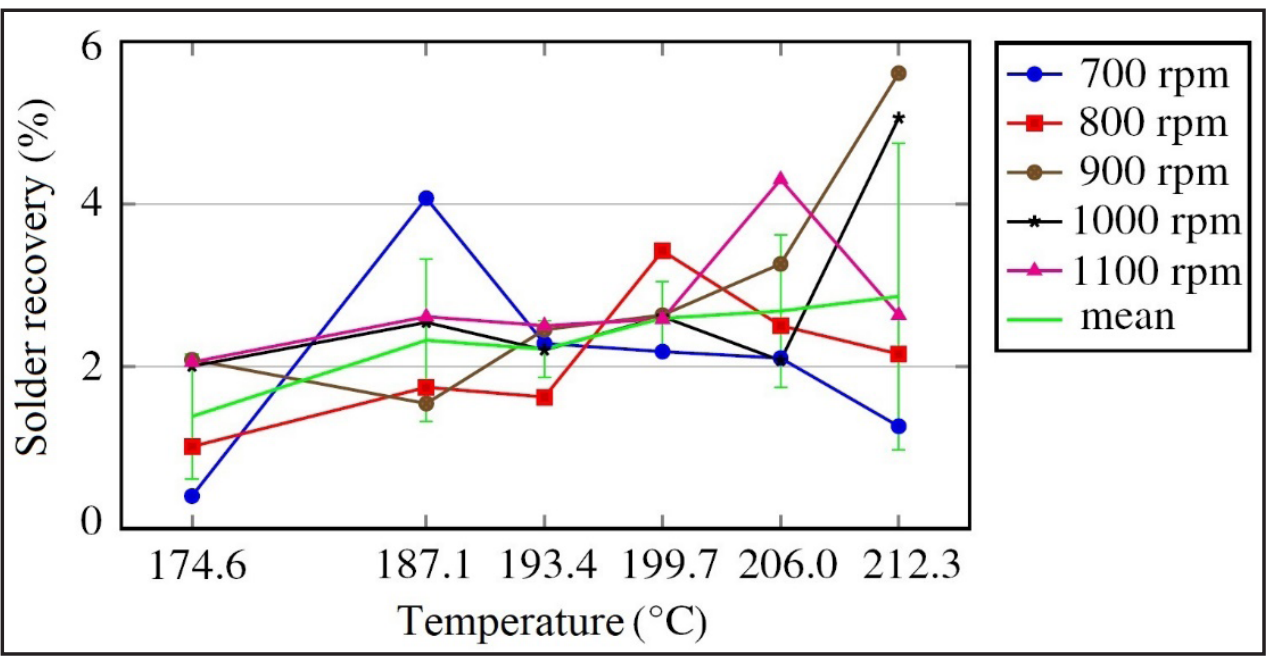


Figure 7 - EC recovery rates during PS-PCB disassembly

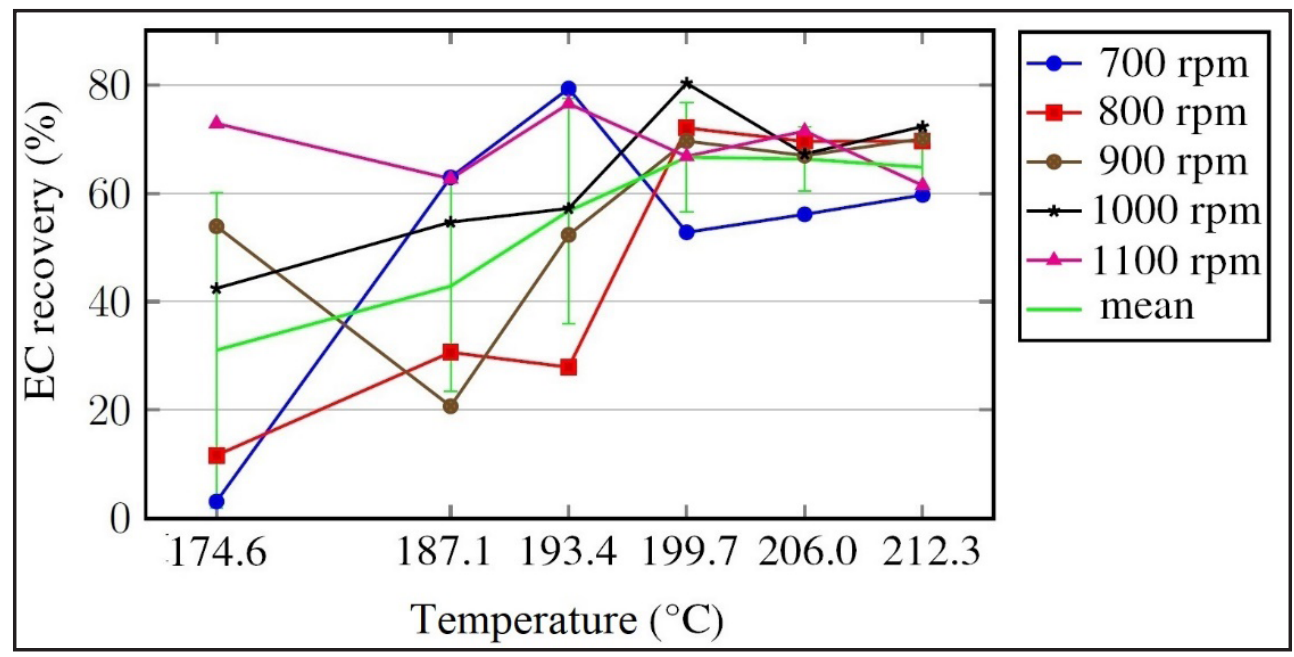

Figure 8 - EC recovery rates during PS-PCB disassembly at $900 \mathrm{rpm}$

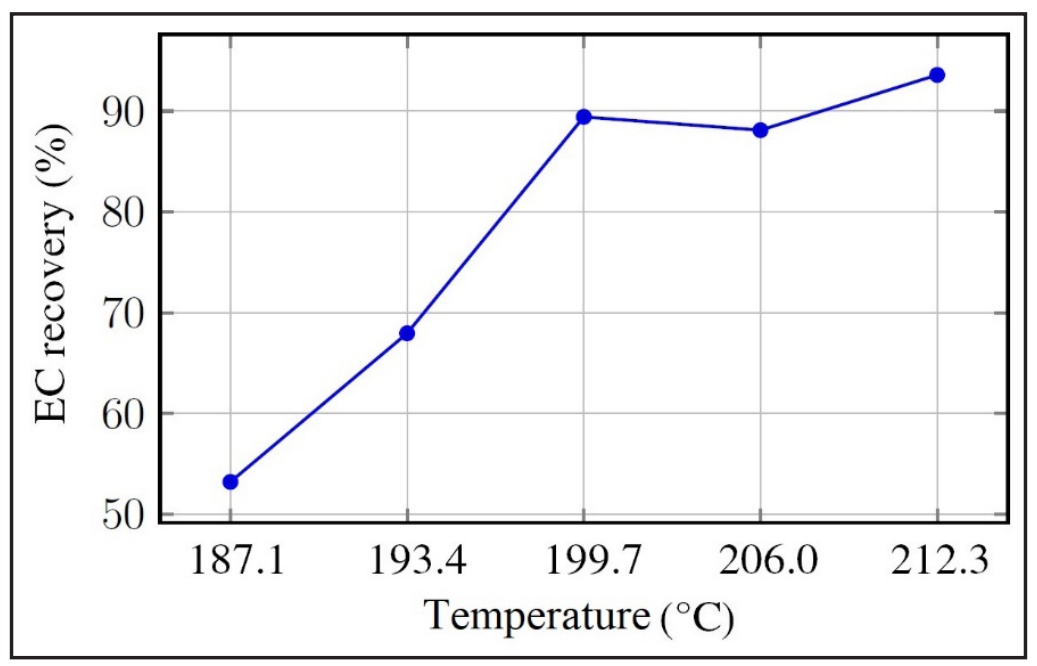

Figure 9 - Material loss of PS-PCB during disassembly

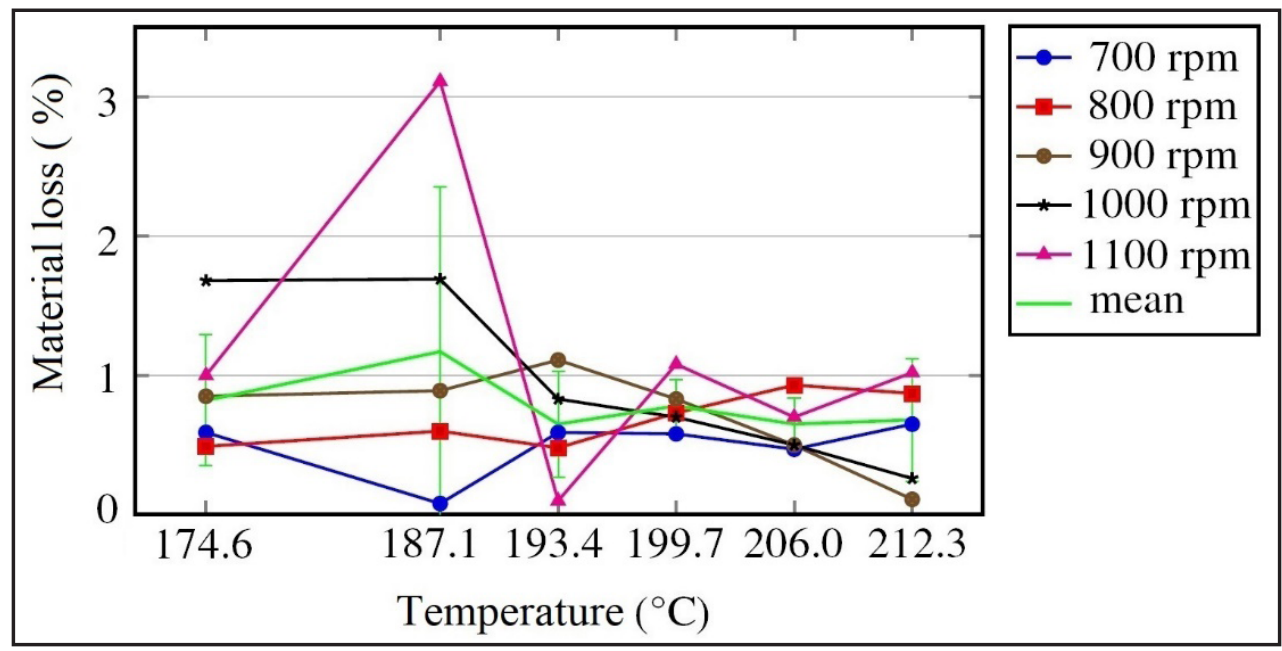


consistent behavior above $900 \mathrm{rpm}$; these results indicate that the equipment has an optimum performance on $t=$ $212,3^{\circ} \mathrm{C}$ - below operating values of Park et al (2015) -,N=900 rpm and, therefore, G around 307,86.

In the particular case of PS boards, EC removal rates at $900 \mathrm{rpm}$ were evaluated and are shown in Figure 8. For temperatures over $199.7^{\circ} \mathrm{C}$, rates of about $90 \%$ or higher were verified; in all these scenarios, removal of ECs that remained attached to the boards could be done using hand tools, and rarely required desoldering.

Material losses were expressed as percentages of material loss in relation to the total weight of the PCBs; they were also analyzed in terms of temperature and rotating speed, as shown in Figure 9.

Material loss rates oscillated mostly between $0.08 \%$ and $1 \%$; that may be associated to small amounts of tin that remained adhered to edges and gaps of the collector's structure, hampering a complete material removal. The separation process may also cause some components to be broken or thrown out of the centrifuge through the gap around its axis, contributing to material loss.

Figure 10 presents a sample of the solder recovered from PS-PCB. The material had uniform color and brightness.
Samples of ECs removed from PCB are shown in Figure 11. A visual inspection demonstrated that, with a few exceptions, the components were not physically damaged during disassembly. EC processing by the method proposed here can be done independently and considering the characteristics of each component. For example, inductors with ferrite core are not stressed at all due to temperature, and may be reused if they receive a new insulation of resin.

The removal ratios of solder and ECs from ME-PCBs also were analyzed as a function of temperature and rotating speed. Figure 12 presents the results for solder recovery; the rates were quite inferior, compared to PS-PCBs which can be traced to the fact that several ME-PCBs had SMD components, which require a smaller amount of solder for fixation.

Figure 13 shows the results for EC removal. Higher temperatures yielded best results, however, when the equipment operated at $1100 \mathrm{rpm}$, recovery rates were very similar regardless of the temperature values.

Material losses in the process were even smaller than in the case of PS-PCBs, barely reaching $0,5 \%$ in most situations, as shown in Figure 14. These low loss rates yielded by the apparatus therefore contribute positively

Figure 10 - Recovered solder of PS-PCB

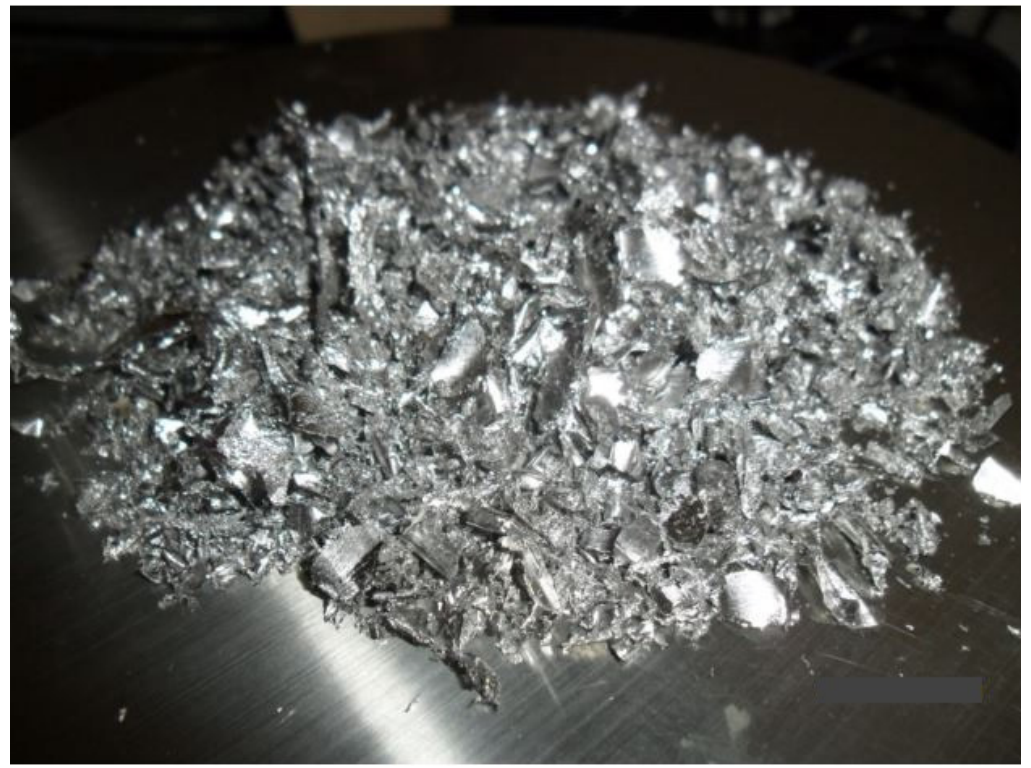

Figure 11 - Electronic components removed from PS-PCB

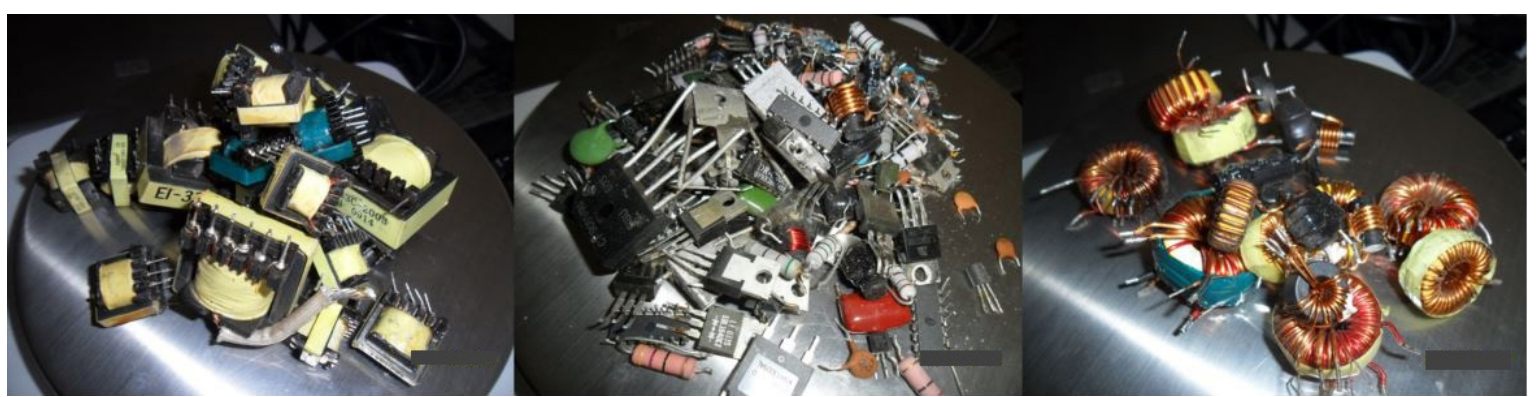


Figure 12 - Solder recovery rates during ME-PCB disassembly

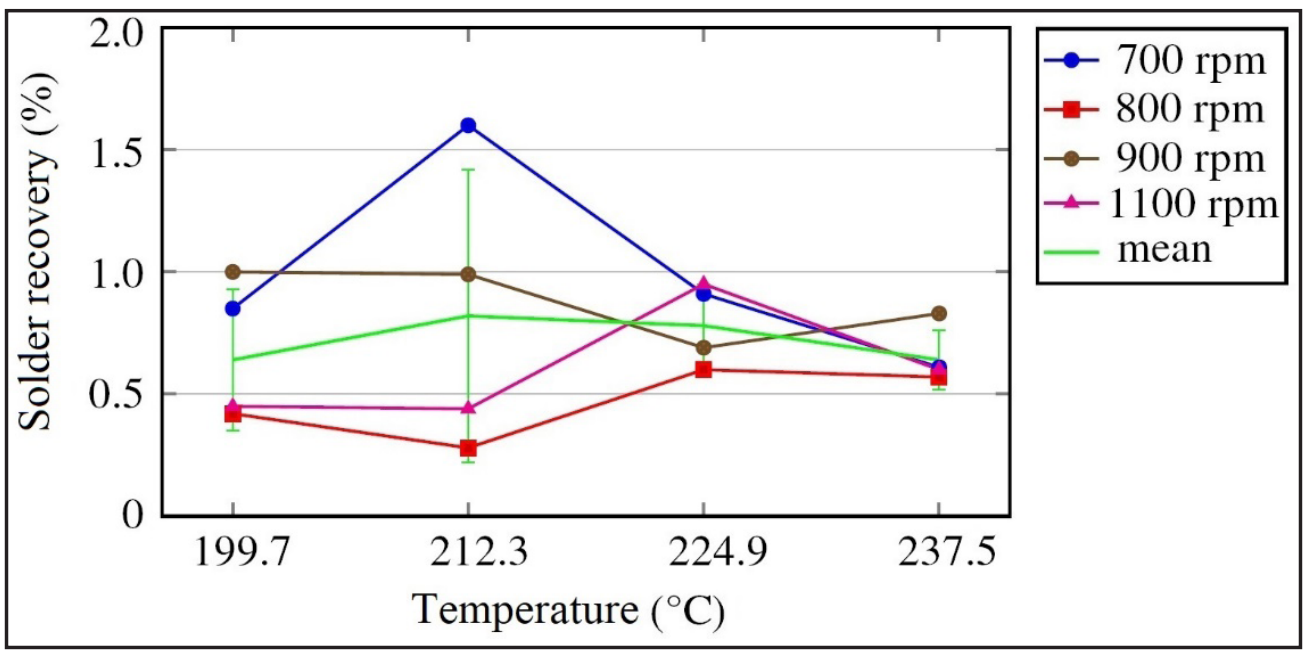

Figure 13 - EC recovery rates during ME-PCB disassembly

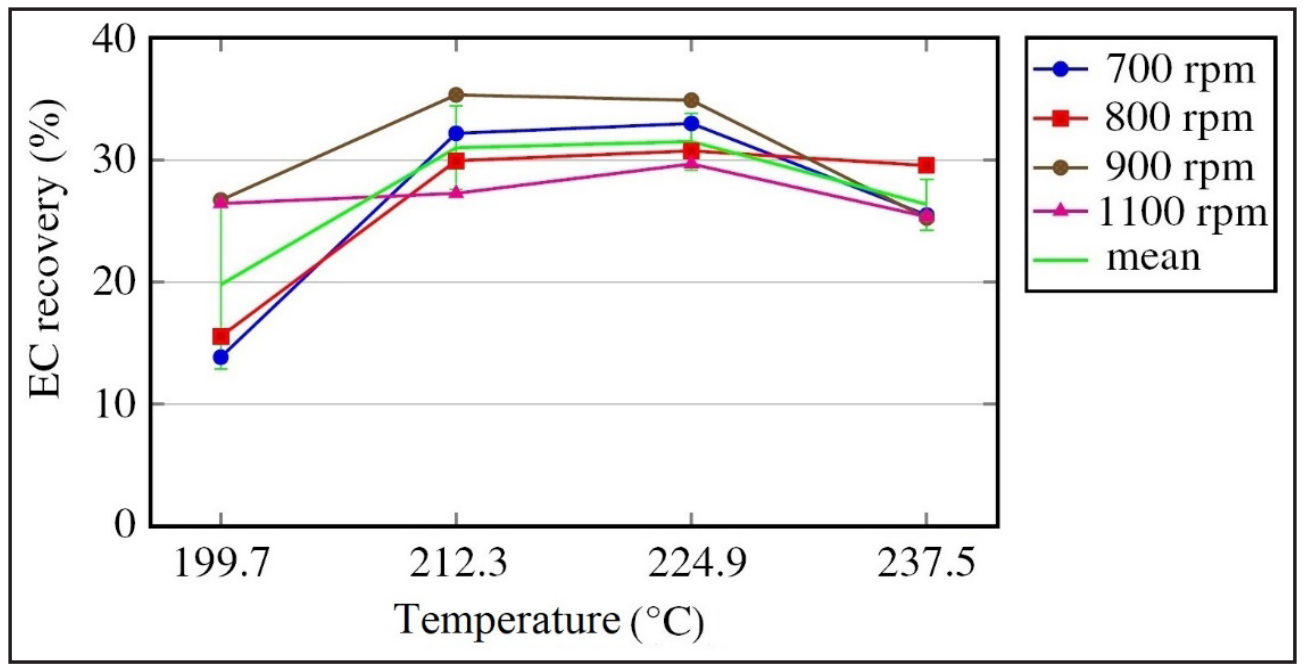

Figure 14 - Material loss of ME-PCB during disassembly

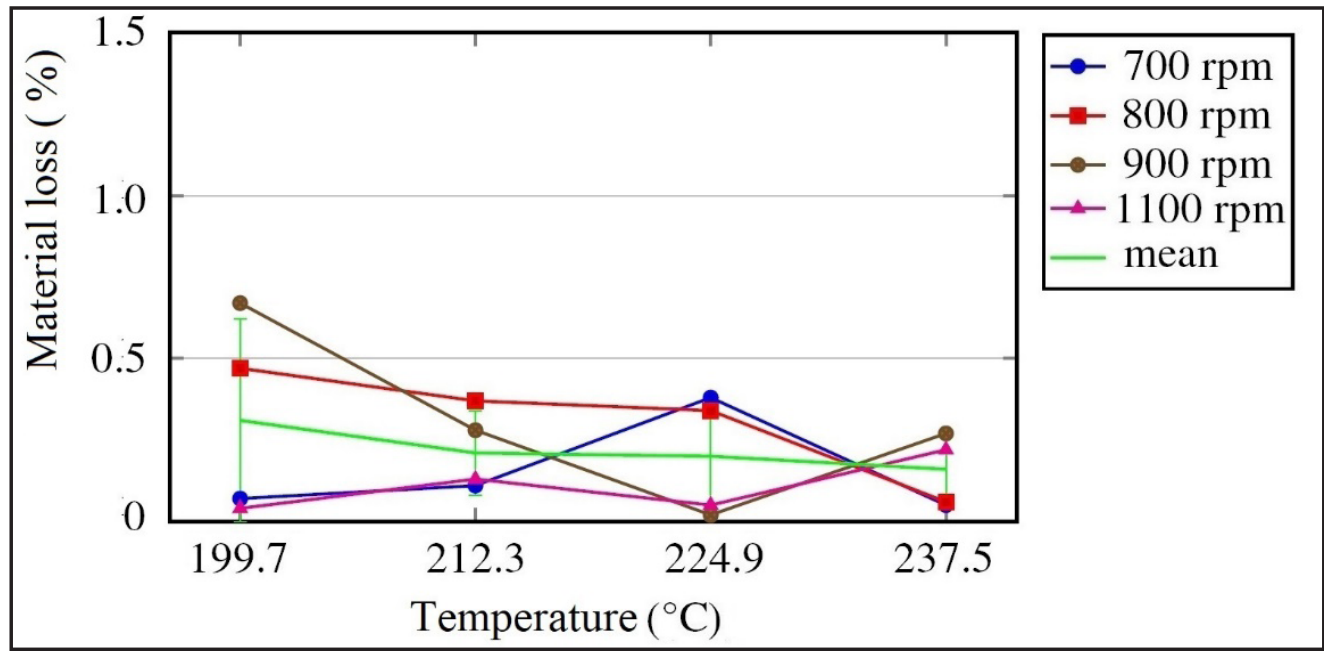


Figure 15 - SEM-EDX image of recovered solder

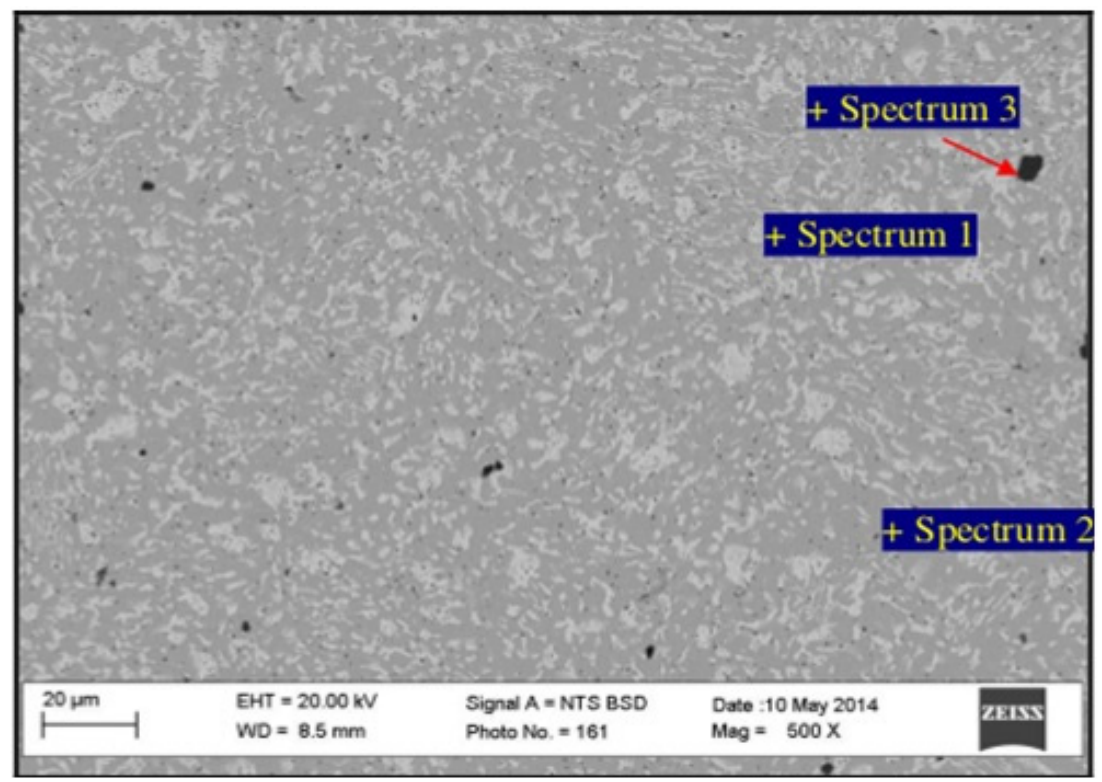

Figure 16 - Composition of recovered solder from PS-PCBs and solder dross

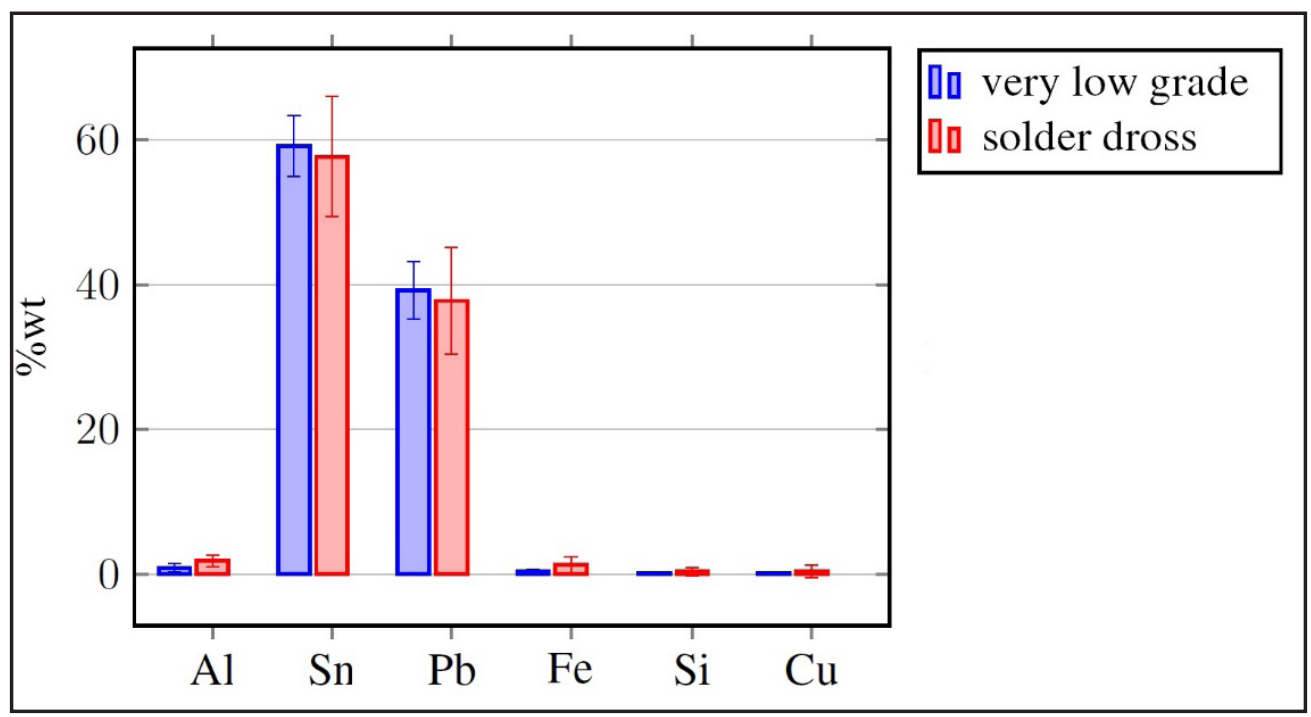

to the total efficiency of the disassembly step and to recovery and recycling operations as whole.

Samples of recovered solder were analyzed using SEM-EDX. Figure 15 is an image of the sample with magnification of 500x, detector BSD and EHT of $20 \mathrm{kV}$. The sample presents three predominant elements distinguished by color: light gray for lead, gray for tin and dark gray for silicon.

The recovered solder was analyzed quantitatively and compared with solder dross generated in industrial soldering process, which is used as input in the production of new solders, and presented a composition similar to the one analyzed by Lucheva et al. (2011).

Chemical compositions of the samples, as shown in Figure 16, indicate that the recovered solder is very similar in composition to the solder dross. Also, the main contaminants are aluminum, iron, silicon and copper for both materials; $\mathrm{Cu}, \mathrm{Si}$ and $\mathrm{Fe}$ are less present in recovered solder than in solder dross, while Al fractions do not differ significantly. This finding subsidizes the direct use of recovered solder from PCBs in the production of new solder.

The study reported here did not address pollutant emissions. The authors acknowledge the importance of assessing emission-related data, but the initial step was to validate PCB disassembly by means of the prototype. However, the process yielded significant recovery values for temperatures around $220^{\circ} \mathrm{C}$, even below the operating values of Wang et al. (2016), so it is possible to infer that emissions were also lower.

The results gain significance once this apparatus might be used to process PCBs derived from other was- 
te streams, such as scrap automotive PCBs - Rosa and Terzi (2016) point out that such PCBs are very similar to PCBs from WEEE and therefore can be treated by the same processes.

\section{Conclusions}

WEEE recycling on developing countries face several drawbacks such as the lack of proper infrastructures for collection and processing. For that reason, WEEE is often sent to large facilities on developed countries that are able to perform more complex processes. PCB disassembly constitutes an operation that can be performed using simpler equipment, on smaller facilities, and significantly contributes to the overall performance of WEEE recycling operations.

The combination or hot air flow and centrifugal force, as performed on the prototype described here, allowed successful PCBs disassembly. Even though solder was recovered at lower rates than other systems, it presented a composition similar to solder dross, indicating it as a potential resource in the production of new solder alloys. This method can also optimize copper recovery from $\mathrm{PCBs}$, once it is the only metal found the substrate. The apparatus also yielded high component removal rates similar to previous prototypes, while operating at lower temperatures; the fact that inductors were not visibly damaged in the process indicates that it can recover some types of components for posterior reuse.

The apparatus can be useful to disassemble PCBs before they are sent to larger facilities, helping establishing this waste stream as a business opportunity for smaller companies, waste pickers and other workers.

Subsequent research should address the emissions of the process, considering the temperature range determined in this research. Further investigations should also assess energy aspects of the disassembly process, confirming that its lower operating temperatures imply less energy consumption. Finally, performances of recovered components should also be investigated closely, in order to assess economic benefits, especially if there is an optimum condition for solder/ component recovery.

\section{Acknowledgements}

We appreciate the support of Environmental Management Superintendence (Superintendência de Gestão Ambiental) and USP-Recicla (São Carlos School of Engineering, University of São Paulo - EESC-USP) on this research.

\section{References}

Almeida, CMVB, Madureira MA, Bonilla SH, Giannetti BF. Assessing the replacement of lead in solders: effects on resource use and human health. J Clean Prod. 2013;47: 457-464.
Bigum M, Brogaard L, Christensen, TH. Metal recovery from high-grade WEEE: a life cycle assessment. J Hazard Mater. 2012;207-208: 8-14.

Bleiwas D, Kelly T. Obsolete Computers, "Gold Mines," or High-Tech Trash? Resource Recovery from Recycling. United States Department of the Interior / United States Geological Survey. 2001.

Brandstotter M, Knoth R, Kopacek B, Kopacek P. Case study of a printed-wire-board concerning (re)design for environment. IEEE T Electron Pack. 2004;27(1): 26-32.

Chen M, Wang J, Chen H, Ogunseitan OA, Zhang M, Zang $\mathrm{H}, \mathrm{Hu}$ J. Electronic Waste Disassembly with Industrial Waste Heat. Environ Sci Techol. 2013;47(21): 12409-12416.

Cui J, Forssberg E, Mechanical recycling of waste electric and electronic equipment: a review. J Hazard Mater. 2003;99(3): 243-263.

Das A, Vidyadhar A, Mehrotra SP. A novel flowsheet for the recovery of metal values from waste printed circuit boards. Resour Conserv Recy. 2009;53(8): 464-469.

Dias P, Machado A, Huda N, Bernardes AM. Waste electric and electronic equipment (WEEE) management: A study on the Brazilian recycling routes. J Clean Prod. 2018;174: 7-16.

Duan C, Wen X, Shi C, Zhao Y, Wen B, He Y. Recovery of metals from waste printed circuit boards by a mechanical method using a water medium. J Hazard Mater. 2009;166(1): 478-482.

Duan H, Li J, Liu Y, Yamazaki N, Jiang W. Characterization and inventory of PCDD/Fs and PBDD/Fs emissions from the incineration of waste printed circuit board. Environ Sci Technol. 2011;45(15): 6322-6328.

Feldmann K, Scheller H. Disassembly of electronic products. IEEE Int Symp Electr. 1994:81-86.

Feldmann K, Scheller H. The printed circuit board - A challenge for automated disassembly and for the design of recyclable interconnect devices. Conference on clean electronics products and technology, 1995:186-190.

Furuuchi, M., Gotoh, K. Shape separation of particles, Powder Technol, 1992;73(1): 1-9.

Ghosh B, Ghosh, MK, Parhi P, Mukherjee PS, Mishra BK. Waste Printed Circuit Boards recycling: an extensive assessment of current status. J Clean Prod. 2015;94: 5-19.

Guo J, Zhang R, Xu Z. Polybrominated diphenyl ethers (PBDEs) emitted from heating machine for waste printed wiring boards disassembling. Procedia Environ Sci. 2016;31: 849-854. 
Hagelüken C. Recycling of Electronic Scrap at Umicore's Integrated Metals Smelter and Refinery. World of Metallurgy - ERZMETALL. 2006;59 (3): 152-161.

Hanafi J, Jobiliong E, Christiani A, Soenarta DC, Kurniawan J, Irawan J. Material recovery and characterization of PCB from electronic waste. International Conference on Asia Pacific Business Inovation and Technology Management. 2012;57: 331-338.

Hino T, Agawa R, Moriya Y, Nishida M, Tsugita Y, Araki $\mathrm{T}$. Techniques to separate metal from waste printed circuit boards from discarded personal computers. J. Mater Cycles Waste Manag. 2009;11(1): 42-54.

Iji M, Yokoyama S, Recycling of printed wiring boards with mounted electronic components. Circuit World. 1997;23(3): 10-15.

Kaya M. Recovery of metals and nonmetals from electronic waste by physical and chemical recycling processes. Waste Manage. 2016;57: 64-90.

Kaya M. Waste Printed Circuit Board (WPCB) recovery technology: disassembly and desoldering approach. Reference Module in Materials Science and Materials Engineering, Elsevier. 2018.

Koyanaka S, Ohya H, Hitoshi S, Endoh S, Iwata H, Ditl P. Recovering copper from electric cable wastes using a particle shape separation technique. Adv Powder Technol. 1997;8(2): 103-111.

Layiding W, Dong X, Peng M, Guanghong D. Disassembling approaches and quality assurance of electronic components mounted on PCBs. IEEE Int Symp Electr. 2005;116-120.

Lee J, Kim Y, Lee JC. Disassembly and physical separation of electric/electronic components in printed circuit boards (PCB). J Hazard Mater. 2012;241-242: 392-399.

Li J, Shrivastava P, Gao Z, Zhang HC. Printed circuit board recycling: a state-of-art survey. IEEE $\mathrm{T}$ Electron Pack. 2004;27(1): 33-42.

Li P, Shi Y, Liu D. Status and Prospect of Disassembly Process of Electronic Components on Waste PCBs. Appl Mech Mater. 2014:599-601;1989-1992.

Long L, Sun S, Zhong S, Dai W, Liu J, Song W. Using vacuum pyrolysis and mechanical processing for recycling waste printed circuit board. J Hazard Mater. 2010;177(13): 626-632.

Lucheva B, Tsonev T, Iliev P. Recycling of Lead Solder Dross, Generated from PCB Manufacturing. JOM-J Min Met Mat S. 2011;63(8): 18-22.

Lyman T, Gerlach CH. Metals handbook. $8^{\text {th }}$ ed. Cleveland, Ohio: American Society for Metals, 1954. 184 p.
Meng L, Zhong Y, Guo L, Wang Z, Chen K, Guo Z. Hightemperature centrifugal separation of $\mathrm{Cu}$ from waste printed circuit boards. J Clean Prod. 2018a;199: 831-839.

Meng L, Zhong Y, Guo L, Wang Z, Chen K, Guo Z. Lowtemperature melting and centrifugation of lead and tin from metal-rich particles of crushed waste printed circuit boards. Chem Eng Process. 2018b;130: 192-200.

Park S, Kim S, Han Y, Park J. Apparatus for electronic component disassembly from printed circuit board assembly in e-wastes. Int J Miner Process. 2015;144: 11-15.

Park YJ, Fray DJ. Recovery of high purity precious metals from printed circuit boards. J Hazard Mater. 2009;164(23): 1152-1158.

Puckett J, Smith T. Exporting harm: the high-tech trashing of Asia. The Basel Action Network, San Jose / Silicon Valley Toxics Coalition, Seattle. 2002.

Rocchetti L, Amato A, Beolchini F. Printed circuit board recycling: A patent review. J Clean Prod. 2018;178: 814-832.

Rosa P, Terzi S. Comparison of current practices for a combined management of printed circuit boards from different waste streams. J Clean Prod. 2016;137: 300-312.

Statista. Shipment forecast of laptops, desktop PCs and tablets worldwide from 2010 to 2022 (in million units). Available from: https:/www.statista.com/statistics/272595/ global-shipments-forecast-for-tablets-laptops-anddesktop-pcs/.

UNEP - United Nations Environmental Programme. Recycling - From e-waste to resources - Final Report. Sustainable Innovation and Technology Transfer Industrial Sector Studies. 2009.

Veit HM, Bernardes AM, Ferreira JZ, Tenório JAS, Malfatti CF. Recovery of copper from printed circuit boards scraps by mechanical processing and electrometallurgy. J Hazard Mater. 2006;137(3): 1704-1709.

Veit HM, Pereira CC, Bernardes AM. Utilization of magnetic and electrostatic separation in the recycling of printed circuit boards scrap. Waste Manage. 2005;25(1):, 67-74.

Wang H, Zhang, S, Li B, Pan D, Wu Y, Zuo T. Recovery of waste printed circuit boards through pyrometallurgical processing: A review. Resour Conserv Recy. 2017;126: 209-218.

Wang J, Guo J, Xu, Z. An environmentally friendly technology of disassembling electronic components from waste printed circuit boards. Waste Manage. 2016;53(7): 218-224. 
Xu J, Lu S, Fu D. Recovery of hydrochloric acid from the waste acid solution by diffusion dialysis. J Hazard Mater. 2009;165(1-3): 832-837.

Yang J, Xiang D, Wang J, Duan G, Zhang H. Removal force models for component disassembly from waste printed circuit board. Resour Conserv Recy. 2009;53, 448-454.

Youssef C, Ameer S, Hisham A, Naveena S, Saeed N, Taleb I. Recovery of Gold, Silver, Palladium, and Copper from Waste Printed Circuit Boards. Proceedings of the International Conference on Chemical, Civil and Environment engineering (ICCEE'2012), 2012 24-25 mar, Dubai. p. 226-234.

Yu J, Williams E, Ju M. Review and prospects of recycling methods for waste printed circuit boards. IEEE I Symp Sust Sys. 2009;1-5. 